Pak. j. sci. ind. res. Ser. A: phys. sci. 2019 62A(2) 98-103

\title{
Assessment of Volatile Organic Compounds at Gasoline Filling Stations and Possible Impacts on Human Health in Lahore, Pakistan
}

\author{
Saif Ur Rehman Kashif* and Ayesha Hanif \\ Department of Environmental Sciences, University of Veterinary and Animal Sciences, Lahore, Pakistan
}

(received March 7, 2018; revised November 16, 2018; accepted December 4, 2018)

\begin{abstract}
The Lahore city, Pakistan has 400 plus filling stations, which are busy in fuel filling round the clock. During supply, storage and its breathing, filling process, volatile compounds are released to the atmosphere which increase VOCs concentration not only on filling stations but also to adjoining areas. These VOCs especially benzene/toluene is reported to be a potential for smog formation in addition to other causes, which is being observed in this city for last two years since 2016. Six company petrol filling stations (5 pumps for each company) were monitored using Haz Scanner HIM-6000 to measure VOCs near each filling station. Readings were taken at 5 feet and 50 feet distance from fuel dispenser in triplicate from each filling station at a height of 2 feet above ground from selected petrol pumps in morning ( 8 am11:50 am) and after noon time $(12: 30 \mathrm{pm}-3: 30 \mathrm{pm})$ in the month of Oct and Nov, 2017. It was found that VOCs at all stations of Pakistan State Oil (PSO) were higher than others. Further, highest skin irritation was observed in Shell Pakistan (80\%) followed by PSO and Caltex Pakistan. Although Parco Pakistan has also longer working time but workers have no skin irritation issue.
\end{abstract}

Keywords: air pollution, VOCs, filling stations, health impacts

\section{Introduction}

The volatile organic compounds (VOCs) are widely concerned due to impact on human health and production of photochemical smog and ozone and have great impact on air quality (Cai et al., 2010). VOCs ranges from carbon six to carbon ten compounds $\left(\mathrm{C}_{6}-\mathrm{C}_{10}\right)$ have strong relationship with meteorological parameters and decreasing of contributions of VOCs cause increase in turbulence (Xiang et al., 2012). VOCs are released from underground tanks and refueling of cars (Hassan et al., 2010). Each compound has different behaviour to environmental conditions (temperature). VOCs concentration is mostly high in spring to summer (Baudic et al., 2016).

Major pollutants in urban air pollution are VOCs, oxides of nitrogen, oxides of sulphur and particulate matter and cause severe threats to human health and atmospheric environment. Method for their control depends on their emission sources and nature (Jeek et al., 2017). Xylene and benzene are most abundant. Benzene above international occupational exposure limits with respect to other and occupational air quality at the refueling bay is a health matter (Moolla et al., 2015). VOCs concentration increased with increase in temperature especially toluene shows great increase i.e., the

*Author for correspondence;

E-mail: rehman.kashif@uvas.edu.pk temperature increased from $25{ }^{\circ} \mathrm{C}$ to $50{ }^{\circ} \mathrm{C}$ at $50 \%$ of humidity and the concentration of toluene is increased by 1.07 fold (Yang et al., 2017). Risks of cancer increases in electrochemical workers. This shows the importance of use of abatement technologies for reduction of VOCs levels and to mitigate their impact in the health of workers (Lerner et al., 2012).

Filling workers at petrol stations are also affected due to evaporative losses during filling. Benzene (air borne organic compound) have been recorded near petrol stations above the average level for urban areas (Correa et al., 2012). Based on temperature and wind, concentrations of VOCs may increase or decrease with time. Flow of the wind accelerates the dispersion of the vapour and decreases the concentration around the pumps (Kountouriotis et al., 2014).

VOCs are neurotoxin, cause neuronal death and decrease the cell viability (Fournier et al., 2017). VOCs are not only produced at filling stations during filling petrol but it can also be produced in friction processes like braking in automobiles (Placha et al., 2017). The health risk assessment in Vastra Gotaland region studies relates preterm deaths and asthma due to volatile organic compounds emission (Fridell et al., 2014). There is a strong relationship between direct exposure to VOCs and cardiovascular physiology. VOCs effect cardiovascular system of human rapidly (Shin et al., 2015). 
Lahore is also one of the colonized cities in Pakistan. It is second most dense city in Pakistan and $32^{\text {nd }}$ most populous city of the world (Demographia, 2016). Due to urbanization, air pollution and smog is also becoming a big issue in Lahore. This metropolitan city has more than 400 petrol filling stations in the city to fuel 1.7 million vehicles $24 \mathrm{~h}$ a day throughout the year. This city is experiencing smog for last two years since 2016. This study was planned to estimate contribution of VOCs released from fuel filling stations to smog formation. Health effects of VOCs on workers engaged in petrol filling activities were also collected through questionnaire.

\section{Materials and Methods}

This study was conducted in the Department of Environmental Science, University of Veterinary and Animal Science (UVAS), Lahore. To measure VOCs emissions from petrol stations six petrol supply companies were selected in Lahore viz. Pakistan State Oil (PSO), Shell Pakistan, Total Parco Pakistan Limited, Caltex Pakistan, Attock Petroleum Limited and Hascol Petroleum Limited. Five filling stations of each company were selected randomly throughout the city for monitoring. Haz-scanner (HIM-6000) is a portable system and is easily deployable as an ambient air quality monitor to measure critical US EPA criteria pollutants including nitrogen oxide, sulphur dioxide, Ozone, carbon dioxide, particulates, nitrogen dioxide and VOCs. This instrument was used to measure VOCs near each filling station and readings at 5 feet and 50 feet distance from fuel dispenser were taken in triplicate from each filling station at a height of 2 feet above ground from selected petrol pumps in morning ( $8 \mathrm{am}-11: 50 \mathrm{am})$ and after noon time $(12: 30 \mathrm{pm}-3: 30 \mathrm{pm})$ the in the month of Oct and Nov, 2017. VOCs present in air at a distance of 1 $\mathrm{km}$ from pump were also measured in ambient air on road side. Questionnaires were filled from filling attendants at each filling station to determine health impacts, one from manager and four from the filling attendants of each company. There were 16 measurements done from each pump twice a week for 8 weeks. Data collected was statistically analyzed using SPSS mainly one way ANOVA, correlation and descriptive statistics were applied at questionnaire.

\section{Results and Discussion}

Atmospheric conditions during study period. Atmospheric data for the month of October and November, 2017 is presented in Table 1. The month of Ootober was warm but November was relatively cool. Temperature during the month of October varied from $39^{\circ} \mathrm{C}$ to 16 ${ }^{\circ} \mathrm{C}$ but in Nov, varied between $28{ }^{\circ} \mathrm{C}$ to $8{ }^{\circ} \mathrm{C}$.

VOCs concentration in the morning. The data collected from filling stations of different companies in morning time during the month of Oct \& Nov, 2017 is presented in Fig. 1A. From the data it is clear that fuel supplying company "Pakistan State Oil" has maximum concentration of VOCs at 5 feet (780.4 and $1068.75 \mathrm{ppb}$ ) in two months, respectively. Similarly at 50 feet distance from dispenser this company also has high concentration of VOCs i.e. 325.88 and 831.4 $\mathrm{ppb}$, respectively in two months. It was indicated from results that concentration of VOCs was increased as the temperature becomes low that might be due to less turbulence due to low temperature in November than from October. Lowest concentration of VOCs was observed in Shell Pakistan at 5 feet distance (165.33 and $208.38 \mathrm{ppb}$, respectively) in both months. This company also has low concentration of VOCs at 50 feet distance from dispenser (112.9 and $188.4 \mathrm{ppb}$, respectively). VOCs concentration of other companies were found to be in between the two companies in both months at 5 and 50 feet distance from dispenser.

Table 1. Meteorological data of Lahore during Oct and Nov, 2017

\begin{tabular}{lcllr}
\hline \hline Month & & Temperature & Relative humidity & Pressure \\
\hline Oct-2017 & High & $39{ }^{\circ} \mathrm{C}$ & $94 \%$ & $1020 \mathrm{mbar}$ \\
& Low & $16^{\circ} \mathrm{C}$ & $20 \%$ & $1004 \mathrm{mbar}$ \\
& Avg. & $28^{\circ} \mathrm{C}$ & $56 \%$ & $1010 \mathrm{mbar}$ \\
\hline Nov-2017 & High & $28^{\circ} \mathrm{C}$ & $100 \%$ & $1016 \mathrm{mbar}$ \\
& & & $17 \%$ & $1010 \mathrm{mbar}$ \\
& Low & $8{ }^{\circ} \mathrm{C}$ & $72 \%$ & $1021 \mathrm{mbar}$ \\
& Avg. & $18^{\circ} \mathrm{C}$ & & $17 \%$ \\
\hline \hline
\end{tabular}


VOCs concentration in the evening. Vehicular emission exhaust, fuel evaporation from storage tanks, oil refining, solvent usage in industries, industrial processes and bio-decomposition of waste are considered as main anthropogenic factors contributing towards VOCs in urban areas. Major classes of chemicals emitted into the atmosphere as VOCs include but not limited to alkanes, alkenes, aliphatic and aromatic hydrocarbons and oxygenated VOCs (2-methyl-3-buten-2-ol, acetone, etc.) which can alter the chemistry of atmosphere. VOCs can undergo four main fates when emitted to atmosphere i.e., dispersion, transformation, chemical reactions and deposition. Dispersion helps for transportation and dilution of VOCs over different layers/parcels of air in troposphere. Transformation may result in condensation of gaseous VOCs into organic particles, adsorption on their surface or solution in water droplets. Similarly, physical and chemical reactions convert them into organic and inorganic molecules especially secondary air pollutants which in turn undergo further dispersion and transformation in the atmosphere. There may also be dry and wet deposition of VOCs on water reservoirs
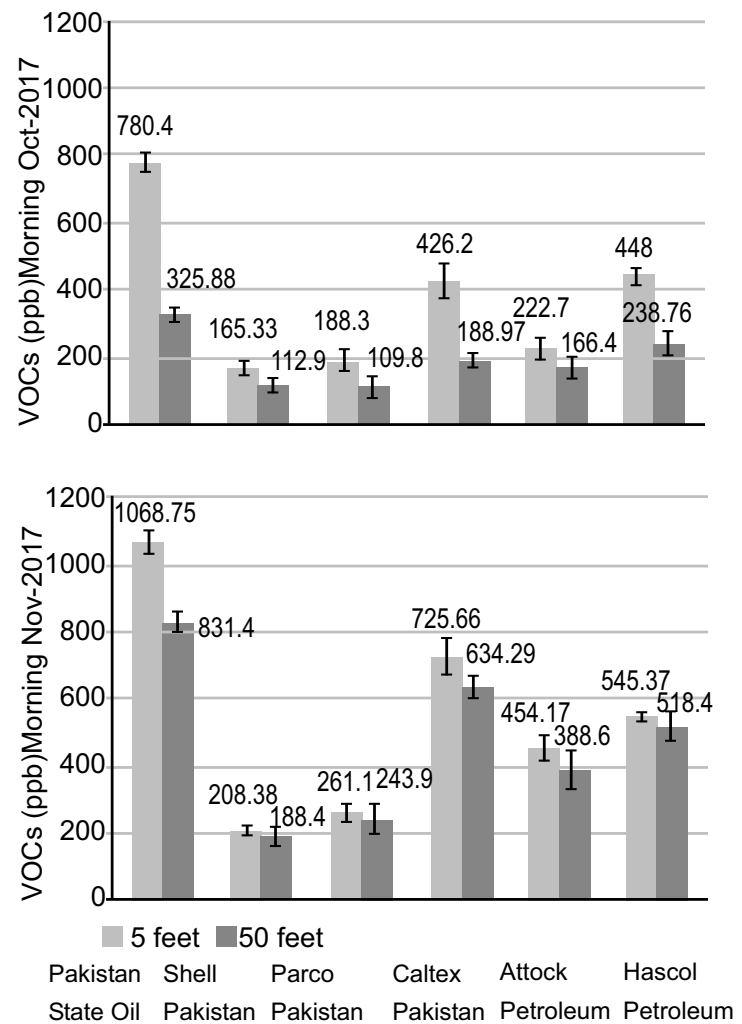

Fig. 1A. VOCs concentration at morning time in Oct-Nov, 2017 and soil through sedimentation and scavenging process. VOCs have a greater role in climate change ie., in secondary organic aerosol (SOA) formations, VOCs as a precursor of ozone $\left(\mathrm{O}_{3}\right)$ formation, photochemical smog and acid deposition. Ozone $\left(\mathrm{O}_{3}\right)$ is a secondary air pollutant formed by the photochemical reaction of the precursor pollutants and primary oxidant to other highly reactive trace gases in the presence of solar UV radiation.

As indicated by the results obtained from VOCs concentration in evening time (Fig. 1B), Shell Pakistan has highest concentration of VOCs in both months at 5 feet distance from dispenser i.e. 1219.1 and 1329.3 ppb, respectively in October and November. Similarly at 50 feet distance, this company has 976.2 and 1188.6 ppb, respectively in two months. The dispersion as indicated by data was more during October as relatively less concentration was observed at 50 feet distance than 5 feet but in the month of Nov, relatively higher concentration of VOCs were observed at 50 feet $(1188.6$ $\mathrm{ppb})$ which was a little bit low than at 5 feet (1329.3
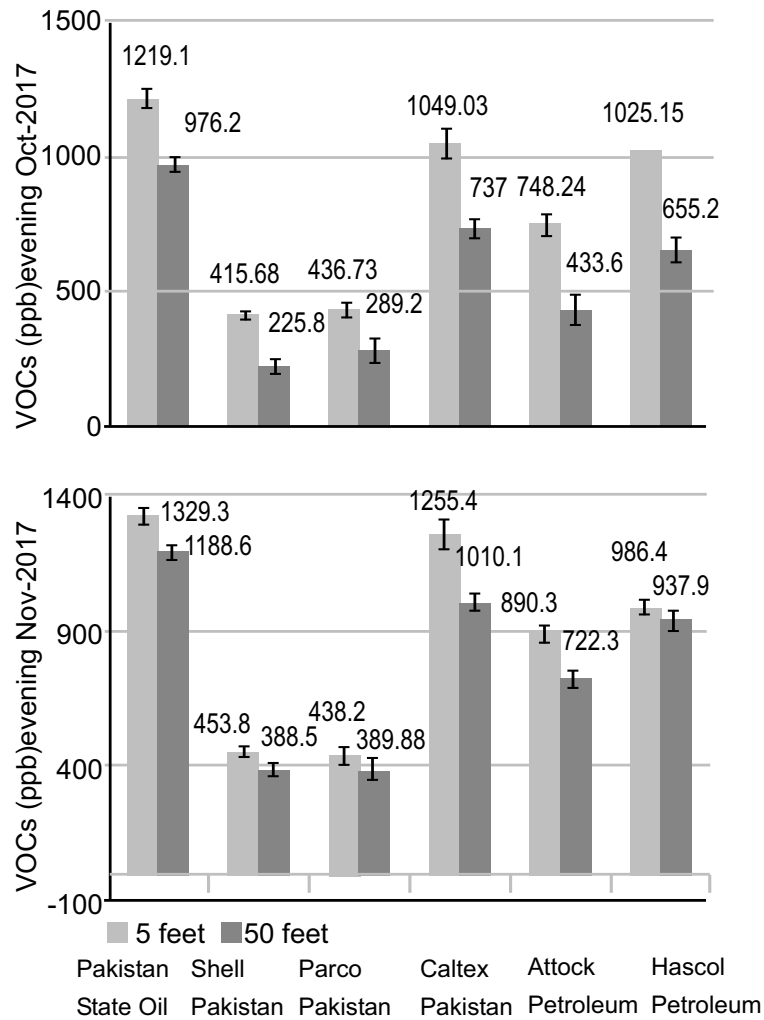

Fig. 1B. VOCs concentration at evening time in Oct-Nov, 2017 
$\mathrm{ppb}$ ). This might be due to relatively higher temperature during October due to which there may be more turbulence in air and VOCs may have higher dispersion in this month. But in November due to fall in temperature, there might be less turbulence in air and all volatiles tend to be having less dispersion and concentrated in the area due to which there was relatively higher concentration at 50 feet in November that at 50 feet distance in October. Caltex Pakistan has also higher concentrations of VOCs in both months at 5 feet (1049.03 and $1255.4 \mathrm{ppb}$, respectively) and at 50 feet (737 and $1010.1 \mathrm{ppb}$, respectively) in October and Novembere. All other companies have lower concentrations of VOCs at 5 feet and 50 feet distance which might be either due to good efficiency of their dispensers or there may be fuel recovery system in operation on these companies.

VOCs concentration at $\mathbf{1} \mathbf{~ k m}$ distance. The results for VOCs concentration at a distance of $1 \mathrm{~km}$ from the filling stations were collected only at evening time and is presented in Fig. 2. The results indicated that relatively more VOCs concentration was observed in the month of October at $1 \mathrm{~km}$ distance from fueling station than in the month of November. It might be due to low temperature and less air turbulence in the atmosphere. It was also observed from the data that PSO and Hascol Petroleum have found to spread more VOCs as conc. of VOCs at $1 \mathrm{~km}$ from both companies was relatively higher (2.1 and $1.71 \mathrm{ppb}$, respectively). Areas surrounding other companies at $1 \mathrm{~km}$ distance are found to have low VOCs concentration which was less than $1 \mathrm{ppb}$.

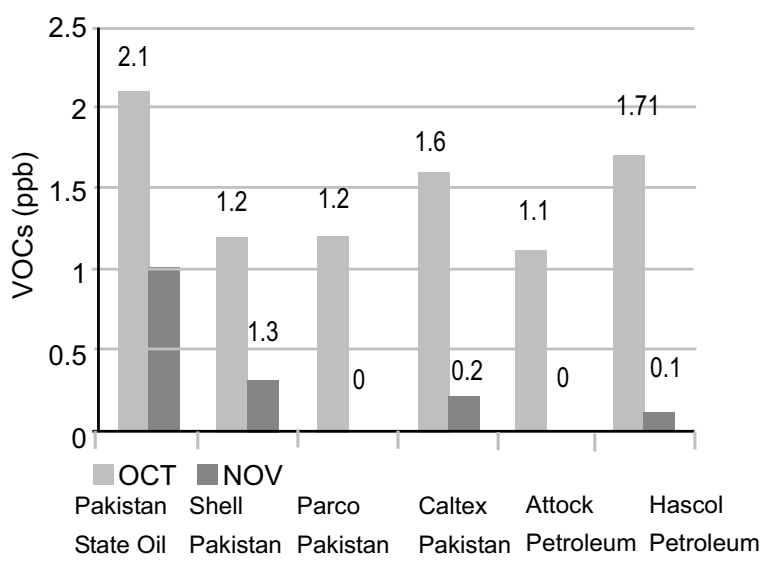

Fig. 2. VOCs conc. at $1 \mathrm{~km}$ distance from fuel station in Oct-Nov, 2017
Health impact on workers. Attention of environmental health research community, environmental regulatory agencies, industries, as well as for the public, VOCs and its public health impacts are drawing rapid concerns. Adverse health impacts of VOCs include eye/throat/nose irritation, headache, nausea and damage to liver, kidney and central nervous system. Benzene, ethyl benzene, toluene, $o-, m$ - and $p$-xylene (BTEX) form a very important group of aromatic VOCs. Benzene is classified by the International Agency for Research on Cancer as Group 1 human carcinogen. Toluene, ethyl benzene, $o$ , $m$-, and $p$-xylene have also been found to develop adverse health impacts on respiratory and neurological effects in humans (Guar et al., 2016).

Health impacts on workers of filling stations and station manager was collected and presented in Fig. 3. The results indicated that $80 \%$ workers have to work longer time daily (11-20 hours) in Shell Pakistan and Hascol Petroleum and Parco Pakistan whereas all other companies workers have relatively shortor working time. As for as health impacts are concerned, highest skin irritation was observed in Shell Pakistan (80\%) followed by PSO and Caltex Pakistan. Although Parco Pakistan has also longer working time but workers have no skin irritation issue. Similarly Attock Petroleum and Hascol Petroleum workers have no such issues of skin irritation. Eye, nose and throat irritation was also found higher in workers of Shell Pakistan $(8 \%)$ as compared to PSO and Caltex. Parco Pakistan, Attock Petroleum and Hascol Petroleum workers have no such issues. It was further found that PSO and Shell Pakistan workers have relatively less asthma issue (60-80\%) than all other companies where workers have developed asthma issue in almost 100\% workers if they work for more than 6 months on petrol pump. It was further concluded that although VOCs were found low on filling stations of Shell Pakistan yet most of the workers on Shell filling stations have severe headache problem during working hours. As reported by other researchers, inhaling vapors cause cough, sore throat and eye irritation to death (Kountouriotis et al., 2014). VOCs are posing severse health issues and their emissions can be regulated by storage and distribution of petrol through applying Vapor Recovery Units and emission reduction measures (Mihajlovic et al., 2016). It is proposed that there should be installation and proper maintenance of vapor recovery systems on filling stations so that VOCs can be recovered with minimal dispersion to atmosphere to reduce VOCs pollution. 

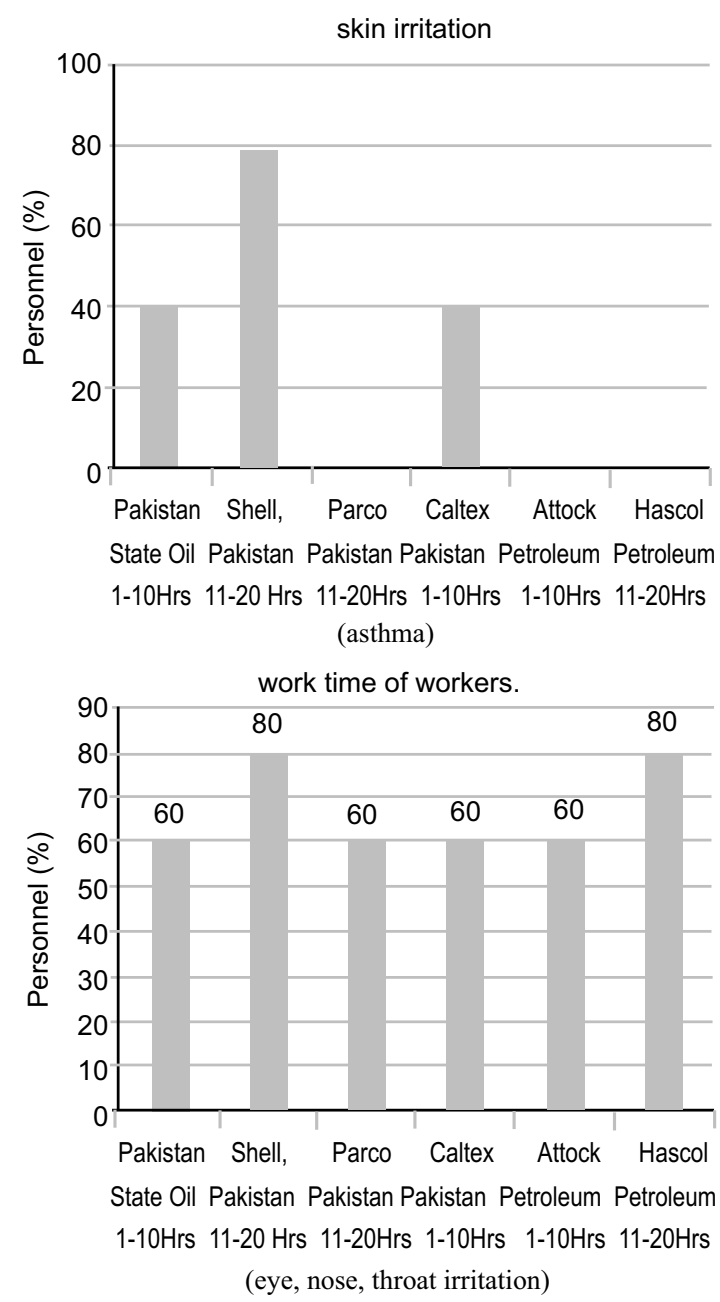

Fig. 3. Work time and health effects on workers in different filling stations

Conflict of Interest. The authors declare no conflict of interest.

\section{References}

Baudic, A., Gros, V., Sauvage, S., Locoge, N., Sanchez, O., Sarda-Estève, R., Favez, O. 2016. Seasonal variability and source apportionment of volatile organic compounds (VOCs) in the Paris megacity (France). Atmospheric Chemistry and Physics, 16: 11961-11981.

Cai, C., Geng, F., Tie, X., Yu, Q., An, J. 2010. Characteristics and source apportionment of VOCs measured in Shanghai, China. Atmospheric Environment, 44: 5005-5014.

Correa, S.M., Arbilla, G., Marques, M.R., Oliveira, K.M. 2012. The impact of BTEX emissions from gas stations into the atmosphere. Atmospheric Pollution Research, 3: 163-169.

Demographia World Urban Areas. Demographia. 1, April 2016.

Fournier, K., Baumont, E., Glorennec, P., Bonvallot, N. 2017. Relative toxicity for indoor semi volatile organic compounds based on neuronal death. Toxicology Letters, 279: 33-42.

Fridell, E., Haeger-Eugensson, M., Moldanova, J., Forsberg, B., Sjöberg, K. 2014. A modeling study of the impact on air quality and health due to the emissions from E85 and petrol fuelled cars in Sweden. Atmospheric Environment, 82: 1-8.

Gaur, M., Singh, R., Shukla, A. 2016. Volatile organic compounds in India: Concentration and sources. Journal of Civil and Environmental Engineering, 6: 1-7.

Hassan, A., Hashemabadi, S.H., Bayat, M. 2010. Evaluation of gasoline evaporation during the tank splash loading by CFD techniques. International Communications in Heat and Mass Transfer, 37: 907-913.

Jeek, H., Chen, K., Xu, J. 2017. Urban air pollution and control. In: Encyclopedia of Sustainable Technologies. M.A. Abraham (ed.), pp. 243-257, Elsevier, the Netherlands.

Kountouriotis, A., Aleiferis, P.G., Charalambides, A. G. 2014. Numerical investigation of VOC levels in the area of petrol stations. Science of the Total Environment, 470: 1205-1224.

Lerner, J.C., Sanchez, E.Y., Sambeth, J.E., Porta, A. A. 2012. Characterization and health risk assessment of VOCs in occupational environments in Buenos Aires, Argentina. Atmospheric Environment, 55: 440-447.

Mihajloviæ, M., Jovanoviæ, M., Pešiæ, R., Jovanoviæ, J., Milanoviæ, Z. 2016. Volatile organic compounds (VOC) policy innovation in petrochemicals river barge transportation. Journal of Cleaner Production, 112: $1559-1567$.

Moolla, R., Curtis, C.J., Knight, J. 2015. Assessment of occupational exposure to BTEX compounds at a bus diesel-refueling bay: A case study in Johannesburg, South Africa. Science of the Total Environment, 537: 51-57.

Plachá, D., Vaculík, M., Mikeska, M., Dutko, O., Peikertová, P., Kukutschová, F.P. 2017. Release of volatile organic compounds by oxidative wear of 
automotive friction materials. Wear, 376: 705-716. Shin, H.H., Jones, P., Brook, R., Bard, R., Oliver, K., Williams, R. 2015. Associations between personal exposures to VOCs and alterations in cardiovascular physiology: Detroit exposure and aerosol research study. Atmospheric Environments, 104: 246-255.

Xiang, Y., Delbarre, H., Sauvage, S., Léonardis, T., Fourmentin, M., Augustin, P., Locoge, N. 2012. Development of a methodology examining the behaviors of VOCs source apportionment with micro-meteorology analysis in an urban and industrial area. Environnemental Pollution, 162: 15-28.

Yang, T., Zhang, P., Xu, B., Xiong, J. 2017. Predicting VOC emissions from materials in vehicle cabins: Determination of the key parameters and the influence of environmental factors. International Journal of Heat and Mass Transfer, 110: 671-679. 